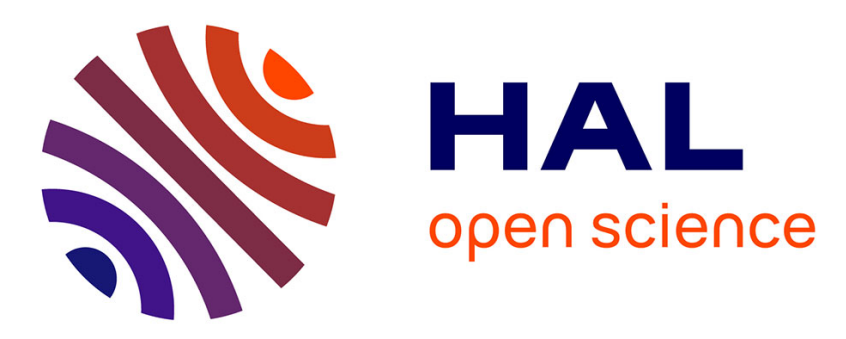

\title{
An Innovative Experimental Study of Corner Radius Effect on Cutting Forces
}

Sébastien Campocasso, Gérard Poulachon, Jean-Philippe Costes, Stéphanie Bissey-Breton

\section{- To cite this version:}

Sébastien Campocasso, Gérard Poulachon, Jean-Philippe Costes, Stéphanie Bissey-Breton. An Innovative Experimental Study of Corner Radius Effect on Cutting Forces. CIRP Annals - Manufacturing Technology, 2014, 63 (1), pp.121-124. 10.1016/j.cirp.2014.03.076 . hal-01015374v2

\section{HAL Id: hal-01015374 https://hal.science/hal-01015374v2}

Submitted on 27 Jun 2014

HAL is a multi-disciplinary open access archive for the deposit and dissemination of scientific research documents, whether they are published or not. The documents may come from teaching and research institutions in France or abroad, or from public or private research centers.
L'archive ouverte pluridisciplinaire HAL, est destinée au dépôt et à la diffusion de documents scientifiques de niveau recherche, publiés ou non, émanant des établissements d'enseignement et de recherche français ou étrangers, des laboratoires publics ou privés. 


\title{
An innovative experimental study of corner radius effect on cutting forces
}

\author{
Sébastien Campocasso a,b,*, Gérard Poulachon (2)a, Jean-Philippe Costes a, Stéphanie Bissey-Breton (3) \\ ${ }^{a}$ Arts et Metiers ParisTech, LaBoMaP, Rue Porte de Paris, 71250 Cluny, France \\ ${ }^{b}$ CEA, DAM, Valduc, 21120 Is-sur-Tille, France
}

Submitted by I.S. Jawahir (1), University of Kentucky, Lexington, KY, USA

The cutting forces are often modelled using edge discretisation methodology. In finish turning, due to the smaller corner radii, the use of a local cutting force model identified from orthogonal cutting tests poses a significant challenge. In this paper, the local effect of the corner radius $r_{\varepsilon}$ on the forces is investigated using a new experimental configuration: corner cutting tests involving the tool nose. The results are compared with inverse identifications based on cylindrical turning tests and elementary cutting tests on tubes. The results obtained from these methods consistently show the significant influence of the corner radius $r_{\varepsilon}$ on the cutting forces.

Keywords: Cutting, Force, Tool geometry

\section{Introduction}

The prediction of the cutting forces is of prime importance to ensure the machined part quality. At a large scale, the cutting force modelling allows the simulation of the workpiece deformation and vibrations. Furthermore, it enables the machining equipment scaled as the clamping system. At a lower scale, the surface integrity can be estimated from the local load applied by the tool on the workpiece material.

In this paper, a new experimental procedure is presented through a study of the effect of the corner radius on the local forces, with the objective to improve the forces predictions.

The corner radius $r_{\varepsilon}$ of the cutting tool, also known as the nose radius, is an important parameter for achieving desired performance in turning operations. The roughness of the machined surface is obviously impacted by the value of this parameter [1]. For a given set of operative parameters $\left(f, a_{p}\right)$, an increase of the corner radius reduces the peak height and changes the chip flow direction, and so limits the risk of chip scratching the machined surface. However, the cutting forces are also highly influenced, as the passive force increases at the expense of the feed force [2], which may generate excessive bending of the workpiece. Thus, a significant influence of $r_{\varepsilon}$ on the dynamic behaviour has been observed by some authors [3-4]. Focusing on the cutting edge, the evolution of the tool-wear can be modified by the value of the corner radius $[2,5]-$ due to the change in the local distribution of the uncut chip thickness -. Also, the residual stresses generated in the machined surface layer, induced by the geometry of the tool, may be affected [5-6].

As the effect of the nose radius on the part quality has been pointed out in several papers, the local influence of this parameter therefore deserves to be studied. Indeed, the cutting force modelling is a first step towards the prediction of the workpiece geometry and surface integrity.

In complex cutting operations, the edge discretisation methodology, presented in Figure 1 , is very helpful in determining the global forces and for estimating the local forces. This methodology allows the generalisation of the cutting force model for any machining operation from a local cutting model [7].

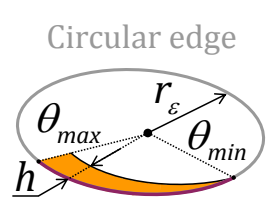

Active edge

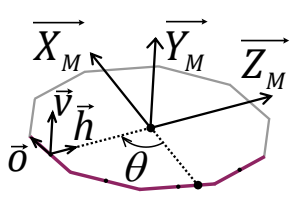

Active segments

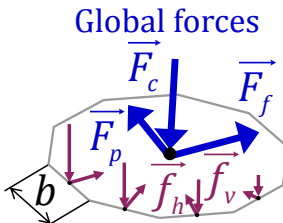

Local forces
Figure 1. Edge discretisation principle, illustrated in the case of a cylindrical turning operation with a round tool insert.

The linear forces (in $\mathrm{N} / \mathrm{mm}$ ) - denoted with a lowercase $f$ in the present paper - are linked to the local geometrical parameters, as the uncut chip thickness $h$, by a local cutting model, of which one of the most popular $[4,7-8]$ is given by Equation (1) and can be justified by orthogonal cutting tests [9].

$f_{v}=K_{c v} h+k_{e v}$ and $f_{h}=K_{c h} h+k_{e h}$

The four coefficients $\left(K_{c v}, k_{e v}, K_{c h}, k_{e h}\right)$ of the cutting model can be calibrated by inverse identification from complex cutting tests or obtained from orthogonal cutting data [8]. Thus, in the case of finish turning with round-cornered tools, the discordances between the calibrated model and the one obtained from orthogonal cutting tests - where the cutting edge is straight - can be due to the curvature of the cutting edge.

The curvature of the cutting edge can be taken into account in the cutting models only for modifying the chip flow direction [10]. However, Denkena et al. [11] have observed that the corner radius affects not only the direction of the resultant cutting force, but also the specific cutting force. This ascertainment can be explained by the differences between the uncut chip thicknesses distributions and also by the curvature of the cutting edge.

The objective of the present study is to analyse the effects of the corner radius on the local forces. First, the experimental set-up is presented in Section 2. Then, Section 3 introduces the local study by means of inverse identifications based on cylindrical turning tests. Afterwards, the new elementary cutting configurations are described in Section 4. Finally, in Section 5, all the experimental results are compared and discussed. 


\section{Experimental set-up}

All the experiments have been performed on a 2-axis lathe Somab Transmab 400 at a cutting speed $V_{c}$ of $250 \mathrm{~m} / \mathrm{min}$, with a pure copper ( $\mathrm{Cu}-\mathrm{OFE}$ ) as machined work material.

The forces measurements were made using a piezoelectric dynamometer Kistler type 9121, together with a Kistler 5019 A charge amplifier. The signals have been digitised by a data acquisition card NI PCI-6221 and treated using DasyLab software.

Several cutting inserts, with varying corner radii, have been used in the experimental work. The radii have been measured using a Leica binocular microscope. The measured and nominal values of $r_{\varepsilon}$ and the corresponding tool inserts references are shown in the Table 1.

Table 1 List of cutting tool inserts used in the experiments.

\begin{tabular}{ccc}
\hline$r_{\text {Enominal }}(\mathrm{mm})$ & $r_{\varepsilon \text { measured }}(\mathrm{mm})$ & Insert reference \\
\hline 0.4 & 0.37 & VCGX 160404-AL H10 \\
0.8 & 0.75 & VCGX 160408-AL H10 \\
1.2 & 1.18 & VCGX 160412-AL H10 \\
2 & 1.94 & VCGX 220520-AL H10 \\
3 & 2.99 & VCGX 220530-AL H10 \\
6 & 6.08 & RCGX 1204M0-AL H10 \\
$\infty$ & - & VCGX 160408-AL H10 \\
\hline
\end{tabular}

The type and the range of inserts have been chosen because of the wide range of corner radii with the same local cutting geometry, as attested by measurements made on a contact profilometer (Somicronic Surfascan 3D). The wedge angle of the tool insert $\beta_{n}$ is equal to $65^{\circ}\left(\gamma_{n}=18^{\circ}\right)$ in all cases and the edge radii $r_{\beta}$ are estimated to be within $13 \mu \mathrm{m} \pm 2 \mu \mathrm{m}$ for $\mathrm{V}$-shaped inserts and $17 \mu \mathrm{m} \pm 2 \mu \mathrm{m}$ for the round insert.

\section{Analysis from cylindrical turning tests}

\subsection{Inverse identification of the local cutting force model}

For each value of $r_{\varepsilon}$, five cylindrical turning tests have been performed, with variable feeds $f$ and depths of cut $a_{p}$ in order to get maximum uncut chip thicknesses on the active cutting edges $h_{\max }$ of the same order of magnitude (between $0.02 \mathrm{~mm}$ and $0.135 \mathrm{~mm}$ ).

Then, the four coefficients of the proposed cutting model (Equation (1)) were identified from these tests by inverse identification, for each value of $r_{\varepsilon}$ (Table 2).

Orthogonal cutting tests on tubes have also been realised in order to identify the model for an infinite corner radius.

Table 2 Identified coefficients of the mechanistic model for different values of corner radii.

\begin{tabular}{ccccc}
\hline $\begin{array}{c}r_{\varepsilon} \\
(\mathrm{mm})\end{array}$ & $\begin{array}{c}K_{c v} \\
\left(\mathrm{~N} / \mathrm{mm}^{2}\right)\end{array}$ & $\begin{array}{c}k_{e v} \\
(\mathrm{~N} / \mathrm{mm})\end{array}$ & $\begin{array}{c}K_{c h} \\
\left(\mathrm{~N} / \mathrm{mm}^{2}\right)\end{array}$ & $\begin{array}{c}k_{e h} \\
(\mathrm{~N} / \mathrm{mm})\end{array}$ \\
\hline 0.4 & 2027 & 17.2 & 802 & 15.6 \\
0.8 & 1679 & 13.7 & 814 & 5.8 \\
1.2 & 1470 & 17.3 & 726 & 8.2 \\
2 & 1427 & 19.9 & 622 & 13.2 \\
6 & 1640 & 16.7 & 741 & 8.4 \\
$\infty$ & 2000 & 5 & 1340 & -15 \\
\hline
\end{tabular}

\subsection{Local influence of the corner radius}

From the models identified previously, it is possible to evaluate the local effect of $r_{\varepsilon}$ as a function of $h$, as presented in Figure 2.

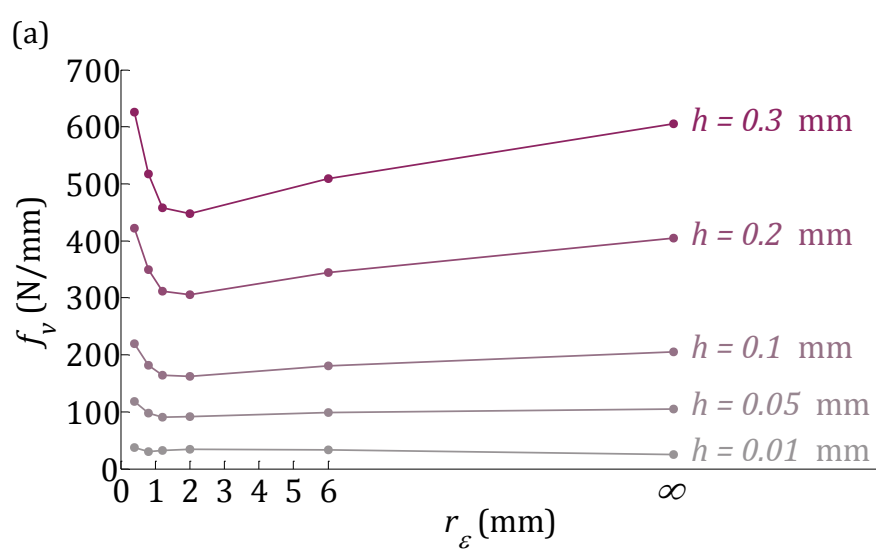

(b)

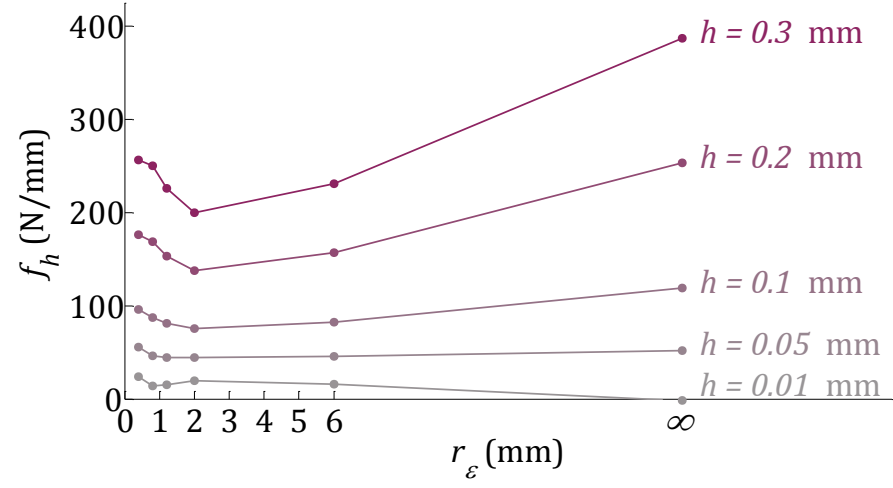

Figure 2. Simulation of the effect of $r_{\varepsilon}$ for different values of $h$ for the force components: (a) $f_{v}$ (cutting force); (b) $f_{h}$ (thrust force).

The effect of $r_{\varepsilon}$ seems to be relevant when the uncut chip thickness is high. The shape of the curves, non-monotonic, suggests that two contradictory phenomena are involved. However, at this step of the analysis, these conclusions must be nuanced, because the highest levels of forces for $r_{\varepsilon}=6 \mathrm{~mm}$ and the rectilinear edge, can be respectively due to the highest edge radius and the effective workpiece radius - which is equal to infinity when orthogonal cutting on tube, as explained in [12]-.

Otherwise, the interpretation of the results remains very difficult and tricky, because several sources of explanation are possible, as the following parameters change from one test to another: the uncut chip thickness distributions along the active cutting edges, the corner radius $r_{\varepsilon}$ and the engagement angle $\Delta \theta_{S A}\left(\Delta \theta_{S A}=\theta_{\max }-\theta_{\min }, \mathrm{cf}\right.$. Figure 1$)$ or the length of the active cutting edge $l_{S a}$. That is why elementary cutting tests allowing decoupling the effects of each parameter have been developed.

\section{Validation with elementary cutting tests in the nose}

\subsection{Principle}

The main objectives of these tests are to directly measure the effect of the cutting edge curvature as a function of the uncut chip thickness, and also to determine whether the engagement angle $\Delta \theta_{S A}$ is a relevant variable.

As shown in Figure 3, the elementary tests have been performed using two cutting configurations: either by cutting a tube or a corner. The principle of the corner tests has been already used with a rectilinear cutting edge and an axial feed rate, in order to study the effect of the cutting edge angle $\kappa_{r}$ on the local forces [12]. 
(a)

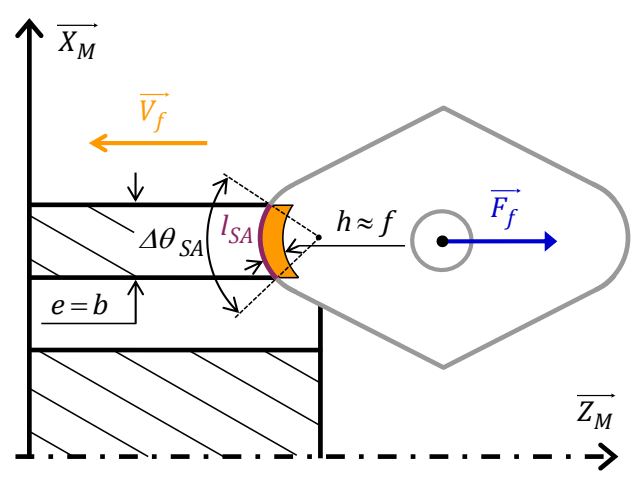

(b)

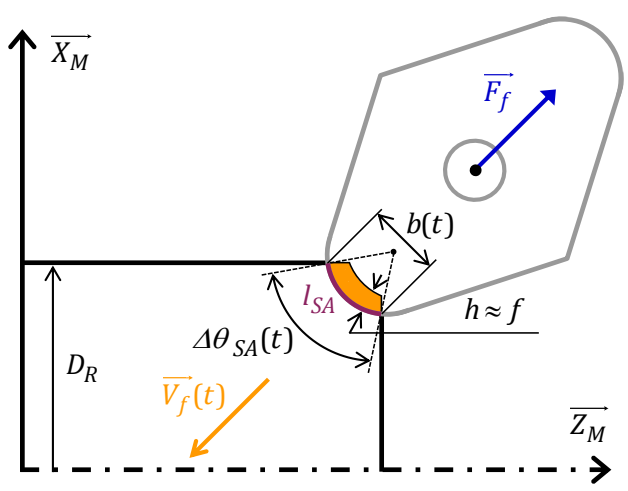

Figure 3. Configurations of the elementary cutting tests in the nose: (a) Tube; (b) Corner.

For both configurations, the uncut chip thickness $h$ along the active cutting edge can be expressed, on the main part of the edge, using Equation (2); where $\theta$ is the current polar angle defined from the bisectrix.

$$
h(\theta)=r_{\varepsilon}+f \cos \theta-\sqrt{r_{\varepsilon}^{2}-f^{2} \sin ^{2} \theta}
$$

As these tests must reflect the cutting behaviour for a given uncut chip thickness, the maximum variation accepted of $h$ with respect of the feed $f$ is equal to $10 \%$, which corresponds approximately to an engagement angle $\Delta \theta_{S A}$ of $60^{\circ}$, or a width of cut $b$ equal to $r_{\varepsilon}$, for $f=0.1 \mathrm{~mm} / \mathrm{rev}$. Consequently, this limitation can result in tests with very narrow tube thickness $e$ (Figure 3 (a)). Therefore, this configuration has been used only for $r_{\varepsilon}$ equal to 2, 3 and $6 \mathrm{~mm}$ (with $e=r_{\varepsilon}$ ). Moreover, only one value of $\Delta \theta_{S A}$ is tested for each value of $e$.

The second configuration involves machining the corner of a cylindrical workpiece with a feed direction oriented at $45^{\circ}$ relative to the machine axis, as shown in Figure 3 (b). This configuration has the advantage of varying continuously $\Delta \theta_{S A}$ during a single test. In return, the measured global forces must be divided by the instantaneous length of the active cutting edge $I_{s a}$. The formulas necessary to process the signals and then obtain the results are given hereafter.

\subsection{Analysis of the cutting tests on the corner}

Let $s$ be the curvilinear abscissa along the rectilinear trajectory, as $s=0$ at the point corresponding to the first contact between the workpiece and the cutting edge.
The cutting time $t_{c}$, expressed in seconds and starting from the beginning of the cut, can be written as in Equation (3).

$t_{c}=\int_{0}^{s(t c)} \frac{60}{V_{f}(s)} \mathrm{d} s$

The feed speed $V_{f}$ increases continuously during the test and can be calculated using Equation (4).

$V_{f}(s)=f N(s)=\frac{1000 V_{c} f}{\pi\left(D_{R}-\sqrt{2} s\right)}$

By integrating Equation (3), the position $s$ is finally expressed as a function of the time (Equation (5)).

$s(t)=\frac{1}{\sqrt{2}}\left(D_{R}-\sqrt{D_{R}^{2}-2 \sqrt{2} \frac{1000 V_{c} f}{60 \pi} t}\right)$

Then, the width of cut $b$ and the engagement angle $\Delta \theta_{S A}$ can be respectively calculated according to Equations (6) and (7).

$b(t)=s(t)-r_{\varepsilon}+\sqrt{r_{\varepsilon}^{2}+2 r_{\varepsilon} s(t)-s^{2}(t)}$

$\Delta \theta_{S A}(t)=2 \arcsin \frac{b(t)}{2 r_{\varepsilon}}$

Finally, the Equation (8) allows the calculation of the instantaneous length of the active cutting edge $l_{s a}$.

$l_{S a}(t)=r_{\varepsilon} \Delta \theta_{S A}(t)$

The comparison of the force chronograms for $F_{X}$ and $F_{Z}$ components confirms that the cutting configuration is symmetric, because these two forces are almost equal. Thus, the feed force $F_{f}$ corresponds to the resultant force in the reference plane $P_{r}$.

The linear cutting force $f_{v}$ can be directly obtained by dividing the measured cutting force $F_{c}$ (or $F_{y}$ ) by the length of the active cutting edge $l_{S a}$ at the corresponding time.

Concerning the thrust force $f_{h}$, normal to the cutting edge in $P_{r}$, the local contribution must be projected in the feed direction. Thus, the feed force is given by Equation (9), which can be easily integrated as $f_{h}$ is assumed to be constant along the cutting edge due to the small variations of $h$; hence the expression of $f_{h}$ from the experimental parameters, given by Equation (10).

$$
\begin{aligned}
& F_{f}=2 \int_{0}^{\frac{\Delta \theta_{S A}}{2}} f_{h} \cos \theta r_{\varepsilon} \mathrm{d} \theta=2 f_{h} r_{\varepsilon} \sin \frac{\Delta \theta_{S A}}{2} \\
& f_{h}(t)=\frac{F_{f \operatorname{mes}}(t)}{2 r_{\varepsilon} \sin \frac{\Delta \theta_{S A}(t)}{2}}
\end{aligned}
$$

During the test, the linear forces first increase and then stabilise. The beginning of the constant part is such that, in all cases, $\Delta \theta_{S A}>20^{\circ}$ and $I_{S a}>0.75 \mathrm{~mm}$, even if no limit values can be defined. The results of the corner tests, presented in the next section, correspond to the mean value of the linear forces $f_{v}$ and $f_{h}$ (obtained by Equation (10)) between $\Delta \theta_{S A}=30^{\circ}$ and $60^{\circ}$. 


\section{Comparison of the results and discussion}

In Figure 4, the results of the two elementary approaches (tube and corner tests), expressed in terms of local linear forces, are compared with the predictions obtained from the calibrated model presented in Section 3 (curves identical to Figure 2), for the only value of uncut chip thickness $h=0.1 \mathrm{~mm}$.

(a)

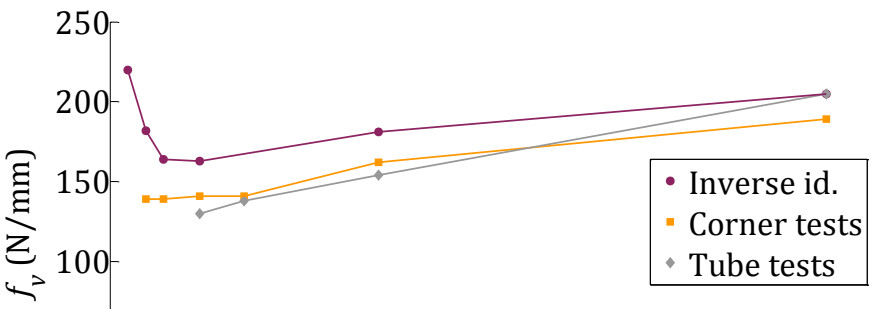

50

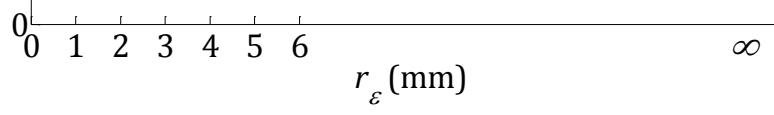

(b)

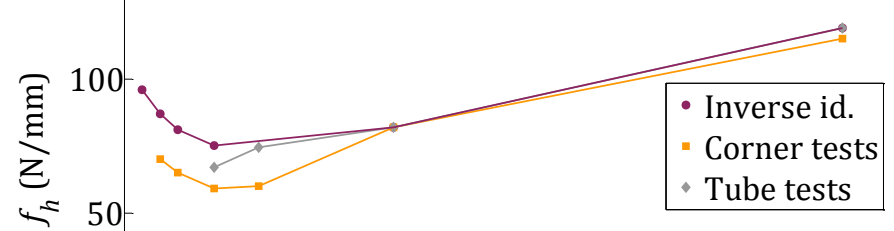

$\begin{array}{lllllllll}0 & 1 & 2 & 3 & 4 & 5 & 6 & r_{\varepsilon}(\mathrm{mm}) & \infty\end{array}$

Figure 4. Comparison of the results of the three approaches, for the force components: (a) $f_{v}$ (cutting force); (b) $f_{h}$ (thrust force).

The force levels and variations are similar in all cases, which thereby validate the methodology of the corner tests. The higher levels obtained from the cylindrical turning tests can be explained by the low values of uncut chip thicknesses unavoidable in this configuration.

It must be noted that the measured forces given by the corner tests conducted with the rectilinear cutting edge are close to those given by the orthogonal cutting tests. Therefore, from the point of view of the cutting forces, it could be a new configuration of orthogonal cutting, with the advantage of not requiring thin specimen.

From the shape of the curves presented in Figure 4, an increase of the corner radius seems to result in a rise of the cutting forces. For smaller radii, the ascent of the curve could be due to a scaling effect linked with the length of the active cutting edge $I_{S a}$. The increase of forces with that of $r_{\varepsilon}$ cannot be explained by a change of the chip formation. Indeed, the material flow to form the chip should be more constrained when the corner radius is low.
It suggests that the influence of the nose radius on the cutting forces finds its origin in the tool-workpiece interaction, by modifying the indentation phenomenon.

\section{Conclusions}

As the influence of the nose radius on the roughness and the residual stresses of the workpiece has been noted in several studies, this parameter deserves to be included in the cutting force models.

In this paper, the effect of the corner radius on the cutting forces has been studied using new original cutting configurations.

The three approaches used - inverse identification, elementary tube and corner tests - show a significant increase of the local cutting forces with the nose radius for the highest values of $r_{\varepsilon}$, which is presumably coming from the indentation between the tool and the generated surface. On the opposite, the increase observed for the smallest values of $r_{\varepsilon}$ could be due to the low lengths of the active cutting edge.

A more detailed analysis of the chip formation and the ploughing effect is needed to understand the physical meaning of the force measurements presented in this paper. Another important parameter in the indentation phenomenon is the edge radius $r_{\beta}$, which can affect both the surface finish and the residual stresses. Therefore, future work should focus on the coupled effect of the corner and edge radii.

\section{Acknowledgements}

The authors would like to acknowledge Florent Trapet for his contribution to this work through his master thesis work.

\section{References}

[1] Childs, T.H.C., Sekiya, K., Tezuka, R., Yamane, Y., Dornfeld, D., Lee, D.E., Min, S., Wright, P.K., 2008, Surface finishes from turning and facing with round nosed tools, CIRP Annals - Manufacturing Technology, Vol. 57/1, pp. 89-92.

[2] Meyer, R, Köhler, J. Denkena, B, 2012, Influence of the tool corner radius on the tool wear and process forces during hard turning, International Journal of Advanced Manufacturing Technology, Vol. 58/9-12, pp. 933-940.

[3] Kuster, F., Gygax, P.E., 1990, Cutting dynamics and stability of boring bars, CIRP Annals - Manufacturing Technology Vol 39/1, pp. 361-366.

[4] Eynian, M., Altintas, Y., 2009, Chatter stability of general turning operations with process damping, Journal of Manufacturing Science and Engineering, Vol. 131/4, 041005 (10 p.), DOI: $10.1115 / 1.3159047$

[5] Liu, M., Takagi, J.I., Tsukuda, A., 2004, Effect of tool nose radius and tool wear on residual stress distribution in hard turning of bearing steel, Journal of Materials Processing Technology, Vol. 150/3, pp. 234-241.

[6] Attanasio, A., Ceretti, E., Giardini, C., 2009, 3D FE modelling of superficial residual stresses in turning operations, Machining Science and Technology, Vol. 13/3, pp. 317-337.

[7] Armarego, E.J.A, Whitfield, R.C., 1985, Computer based modelling of popular machining operations for force and power prediction, Annals of the CIRP, Vol. 34/1, pp. 65-69.

[8] Budak, E., Altintas, Y., Armarego, E.J.A., 1996, Prediction of milling force coefficients from orthogonal cutting data, Journal of Manufacturing Science and Engineering, Vol. 118/2, pp. 216-224.

[9] Armarego, E.J.A, Epp, C.J., 1970, An investigation of zero helix peripheral upmilling, International Journal of Machine Tool Design and Research, Vol. 10/2, pp. 273-291.

[10] Adibi-Sedeh, A.H., Madhavan, V., Bahr, B., 2002, Upper bound analysis of oblique cutting with nose radius tools, International Journal of Machine Tools and Manufacture, Vol. 42, pp. 1081-1094.

[11] Denkena, B., Reichstein, M., Köhler, J., 2006, Influence of the Captured Border on Cutting Forces in Turning Processes. Proc. of the $9^{\text {th }}$ CIRP International Workshop on Modeling of Machining Operations, Bled, Slovenia, pp. 233-238.

[12] Campocasso, S., Costes, J.P., Fromentin, G., Bissey-Breton, S., Poulachon, G., 2013, Improvement of Cutting Forces Modeling Based on Oriented Cutting Tests, Procedia CIRP, Vol. 8, pp. 206-211. 